\title{
Production Planning and stocking of Life-Saving Essential Medicines at Vendor's and Buyer's End [A Real Case Study and Suggested Feasible Solution]
}

\author{
Viranchi A. Shah ${ }^{1}$, Dr Pradeep J. Jha ${ }^{2}$ \\ ${ }^{I}$ (B.Pharm, MBA; Entrepreneur, Hon. Secretary-Indian Drugs Manufacturer's Association GSB, Joint \\ Secretary-Indian Pharmaceutical Association-GSB \& Member- Foreign Trade Committee, Gujarat Chamber \\ of Commerce \& Industry) \\ 2 (M.S. (Mathematics)., Ph.D, CAMET-UK, L. J Institute of Engineering \& Technology, Ahmedabad \& \\ Registered Guide - RAI University)
}

\begin{abstract}
Preface: The author is an entrepreneur engaged in manufacturing and exports of life saving pharmaceutical formulations. He is also an office bearer in several professional associations such as Indian Drugs Manufacturer's Association- Gujarat State Board, Indian Pharmaceutical Association - Gujarat State Board and in Gujarat Chamber of Commerce and Industry.

One of the key challenges faced in international marketing operations by the author's enterprise- Saga Laboratories, was to maintain optimum stocks at the Vendor's and the importer's end in order to avoid shortage of life saving medicines such as antibiotics and anti-malarials.

The company approached Dr Pradeep J. Jha, who already has published papers and done work in the field of inventory management. The purpose was to identify a practically feasible management model to address the issue of production planning and stocking of essential life saving medicines.

Under the guidance of Dr Jha, the study was done and the models were identified and evaluated. The novel concepts detailed in this study paper is an outcome of such efforts. Novel concepts like Safety Plan stock at buyer's end, Emergency stock at vendor's end and No-shortage gain are some of proposed novel concepts that have evolved out of this study and have been successfully implemented. The models were then tested in real life situations by Saga Laboratories for their importers in several Asian, African and South American markets. Owing to successful implementation of this novel business model, it was decided to publish this as a paper and to work further in this direction to come out with newer ideas in this field.

This paper will be followed up with further studies in this direction, such as Order Size optimization, profit optimization etc.
\end{abstract}

\begin{abstract}
Decision related to production and supply of life saving medicines to avoid out-of-stocks situations is very critical. Fundamentals of VMI (Vendor Managed Inventory) and CPFR (Collaborative Planning, Forecasting and Replenishment) are well established concepts. Keeping these as central, the alternatives are sought and implemented to arrive at optimality in terms of solutions to many pending problems.

Many pharmaceutical companies are looking at finding solution to this problem to maintain continuity of their stocks of life saving medicines. This study attempts to provide two alternatives which have proved successful and cost-effective.

The first one is a plan to make a dispatch, at a discount rate and relaxed payment terms, on some additional units (Decision Variable) over and above the buyers order; this will be referred as Safety-Plan in the lines to follow. The second one is to always maintain emergency stock, in proportion to the total order size (Decision Variable) of all buyers, at vendor's end.
\end{abstract}

\author{
Notations And Key Words \\ 1.1 Notations: \\ $\mathrm{A}_{1}$ : Amount of Raw material required \\ $\mathrm{C}_{1}$ : Cost price per unit of $\mathrm{A}_{1}$ \\ $\mathrm{P}_{1}$ : Production Cost per Unit \\ $\mathrm{S}_{1}$ : Sale Price per unit \\ $\mathrm{h}_{1}$ : Holding cost ( per unit per unit time) at vendor's end \\ $\mathrm{h}_{2}$ : Holding cost (per unit per unit time) at buyer's end \\ $F_{1}$ : Transportation Cost per Unit \\ $\mathrm{q}_{\mathrm{i}}$ : Order Size of $\mathrm{I}^{\text {th }}$ buyer \\ $\mathrm{P}_{\mathrm{A}}$ : Production amount in one shot
}


$\mathrm{T}$ : Time slot between two production runs

D: Sales rate at buyer's end

$\mathrm{AC}_{\mathrm{I}}=$ Cost as calculated in the section. $\mathrm{I}=1,2,3 \ldots$ Etc.

Note : some terms like $\mathrm{K}_{1}, \mathrm{~K}_{2}$ etc. are introduced during the calculations These terms, in some cases, eventually become decision variables.

\subsection{Key-Words:}

(1) Emergency Stock (2) Discounted Order Size (3) Carrying Cost (4) Cost-Effectiveness

(5) Expected Delay (6) Safety -Plan( stock) (7) no- shortage gain

ASSUMPTIONS: Some assumptions in this model are very obvious and realistic.

The ones which are specially related in this connection are as follows.

(1) Price or rates of the items remain constant over a period of a time-cycle.

(2) Safety - plan coefficient remains constant and same for all buyers.

(3) The buyer will get the safety-plan stock at a discount rate and will make the payment only when he receives the next lot of items already ordered.

(4) As agreed upon by mutual consent, the buyer, to avoid the risk against probable shortages ,requests the vendor to manufacture and stock some percentage amount of his order size at his end. This is an unconditional request and if agreed upon abides the buyer to pay for the holding cost till the time he places the next order. This is the conditional stock at vendor's end and is referred as 'Emergency Stock'.

(5) Lead-time for vendor for raw material procurement is zero.

(6)Material when exposed need to be used for production purpose. (No storage is technically allowed.)

(7) Production run is taken to meet with accumulated demands of all the buyers.

\section{Introduction:}

In this paper our basic interest is focused on determining the emergency stock at vendor's end and buyer's end. In the case of life-saving drugs, each production run is very costly and involves many time consuming procedural routines. Quality control department, right from purchase of raw material to packing of tablets in strips has an important role to achieve total perfection. It may not be all time possible to take production runs as and when planned and decided. It requires technical planning. In some cases, weather condition play important role in production process. Purchase of raw material from the competitive market and from reliable source are also important factors restricting frequent runs.

Contrary to these factors mentioned above, brand name, long-established reliability, and wide acceptability demand of such medicines either increases or remains steady with many upheavals, not precisely predicted, from time to time.

As a result demand, in this case, and as in its basic nature is a stochastic variable. This very fact making the problem more critical forces us to take decisions of maintaining reserve stock at both ends. This is upon the agreement between the vendor and the buyer that risk of additional purchase is on vendor's end while the buyer shall pay for the holding charges ill a period of his next order. We, on vendor's side, call it 'Emergency Stock' - a fraction of total production amount done in the favor of all buyers' demand-- which is air -lifted to the calling party. This emergency stock is a decision variable. The other part on the buyer's side is a 'Safety Plan' -highly recommended to all the buyers with attractive payment terms. It is a part (Decision variable) or some fraction over and above the total order size the buyer has ordered calculating all his safety stock and expected lead-time demand.

\subsection{BUYERS DEMAND AND SAFETY - PLAN:}

There are $\mathrm{n}$ buyers; we note them as $\mathrm{B}_{1}, \mathrm{~B}_{2}, \ldots . . \mathrm{B}_{\mathrm{n}}$. Buyers, having different sales capacity and different storage capacity, manage their business by placing orders of sizes. Let the order size of different buyers be $\mathrm{q}_{1}, \mathrm{q}_{2}, \ldots . \mathrm{q}_{\mathrm{n}}$.

Total of order sizes $=\mathrm{Q}=\sum_{i=1}^{i=n} q_{i}$

Following the second step approach $=$ Safety Plan, let us say that $\mathrm{K}_{1}$ is an additional supply of medicines which is over and above of the total order size Q. (Result (1)) 
Total supply target $=\left(1+\mathrm{K}_{1}\right) \cdot \mathrm{Q}=\left(1+\mathrm{K}_{1}\right) \cdot \sum_{i=1}^{i=n} q_{i}$

The incremental amount $\left(\mathbf{K}_{\mathbf{1}} \mathbf{Q}\right)$ is the Total Safety - Plan. For each buyer it is in proportion of his order size. [ $\left.\mathrm{K}_{1} \cdot \mathrm{q}_{1}, \mathrm{~K}_{1} \cdot \mathrm{q}_{2}, \ldots \ldots . \mathrm{K}_{1} \cdot \mathrm{q}_{\mathrm{n}}\right)$

It is expected that safety- plan will enable the buyer to meet with (1) sudden demand at any time during his cycle time, (2) any delay in transit time when the vendor has already supplied the buyer his demand that equals ( $\left.1+\mathrm{K}_{1}\right) \mathbf{q}_{\mathbf{I}}$ units ( for any value of $\mathrm{i}=1$ to $\mathrm{n}$ ), and (3) any delay in dispatch from vendor's end.

\subsection{VENDOR'S PLAN AND EMERGENCY STOCK:}

We have already seen that production procedure is not simple as it seems; it requires many procedures like

(1) Procurement of raw material at an affordable rate and from the parties standing well- recorded on the approved list

(2) Approval of raw material from quality control department

(3) Proper set up of machineries capable of uninterrupted production

(4) Quality check-up and approval of finished goods

(5) Packaging and approval by competent authorities before dispatch.

All these factors are critical and any delay or rejection is liable to postpone the entire set-up to an unwarranted delay in the complete chain.

In order to partially or fully meet with some circumstances like these, on the buyer's request, the vendor decides.

Considering all of these factors and their criticalities, the vendor decides, on buyer's request, to be on safer side and thinks of making its approved production set -up to make a production on higher side then the amount requested for. This additional stock produced over and above the total supply target $=\left(1+K_{1}\right)$. $Q$, is called an emergency stock. Like a safety - plan stock, this emergency stock is also some fraction of the total demand. We note this emergency stock by the symbol ' $\lambda$ '. It is mutually agreed upon to dispatch any portion or full lot $\lambda$ units for air- shipment.

With the two reasons shown below, the buyer agrees upon a proposal of paying the holding cost for the emergency stock retained at buyer's end.

(1) The vendor has to go for additional purchase of raw material and also bear the production cost for the emergency stock.. The buyer is not required to contribute any amount towards this plan. In addition the vendor is morally committed to this stock on buyer's urgent call for dispatch.

(2) The holding cost at vendor's end is cheaper then what it is at buyer's end.

$$
\text { Emergency-stock }=\lambda=\mathrm{K}_{2} \cdot \sum_{i=1}^{i=n} q_{i}
$$

. Where, $\mathrm{K}_{2}$ is a decision variable. $0<\mathrm{K}_{2}<1$.

In view of both the Safety- Plan stock and emergency stock, the production amount sizes to

$$
\mathrm{P}_{\mathrm{A}}=\left(1+\mathrm{K}_{1}+\mathrm{K}_{2}\right) \cdot \sum_{i=1}^{i=n} q_{i}
$$

\subsection{All About Raw-Material:}

Let $\mathrm{A}_{1}$ be the amount of raw material that can produce a lot $\mathrm{P}_{\mathrm{A}}$. Let the purchase cost per unit be $\mathrm{C}_{1}$. To safe-guard against any disorder either in quality or changes or of some part of the raw material or production loss due to technical problems; it is always reasonable to order an additional quantity of raw material. On the other end, this additional purchase or a part of it will be useful to make the production of the emergency stock.

Assumption (4) makes the acquisition on demand.

Order size of raw material $=\left(\mathrm{OA}_{1}\right)=\mathrm{P}_{\mathrm{A}}+\mathrm{K}_{4} \cdot \mathrm{P}_{\mathrm{A}}=\left(1+\mathrm{K}_{4}\right) \mathrm{P}_{\mathrm{A}}$ with $0<\mathrm{K}_{4}<1$

This means that to successfully meet the production requirement, the vendor has to purchase of $\mathrm{P}_{\mathrm{A}}$ units, we have to buy a fraction $=\frac{1+k_{4}}{k_{4}}=(1+\varnothing)$ amount in addition to unit amount. As a result of long standing experience, we take $5 \%$ to a maximum of $10 \%$ more amount.

Total Purchase cost of raw material necessary to satisfactorily complete the production run equals to $\mathrm{C}_{1} \cdot\left(\mathrm{OA}_{1}\right)$. We denote this by $\mathrm{P}_{\mathrm{C}}$. 
$\therefore \mathrm{P}_{\mathrm{C}}=\mathrm{C}_{1} \cdot\left(\mathrm{OA}_{1}\right)$

\subsection{ACCOUNTABILITIES OF ALL ADDITIONAL:}

In this section, we identify accountability of all highly necessary additional that we have been mentioning so far.

\subsubsection{What is on vendor's part?}

(1) The vendor incurs purchase cost of additional amount of raw material.

We note this as $\mathbf{A C}_{\mathbf{1}}$.

$$
\mathbf{A C}_{1}=C_{1} .\left[\frac{1+k_{4}}{k_{4}} \cdot \sum_{i=1}^{i=n} q_{i}\right]
$$

Let $\mathrm{K}_{5}=(1+$ ǿ $)$ where $ø=1 / \mathrm{K}_{4}$

$$
\therefore \mathrm{AC}_{1}=\mathrm{K}_{5} . \mathrm{C}_{1} . \sum_{i=1}^{i=n} q_{i}
$$

(2) The vendor incurs production cost of emergency stock. We note this cost as $\mathbf{A} \mathbf{C}_{\mathbf{2}}$.

$$
\mathrm{AC}_{2}=\mathrm{P}_{1} . \mathrm{K}_{5} . \sum_{i=1}^{i=n} q_{i}
$$

(3) The vendor has to bear a loss of interest on the actual cost incurred given by equations (8) and (9) above. This is for a period of one complete cycle time ; say T.

$$
\mathbf{A C}_{\mathbf{3}}=\left(\mathbf{P}_{\mathbf{1}}+\mathbf{C}_{\mathbf{1}}\right) \cdot \mathbf{K}_{\mathbf{5}} \cdot \sum_{i=1}^{i=n} q_{i} \cdot(\mathbf{r} . \mathbf{T})
$$

(4) The vendor bears an additional cost of dispatch of the safety-plan stock. If $F_{1}$ denotes forwarding cost per unit then additional cost, denoted as, $\mathbf{A C}_{4}$ is calculated as follows.

$$
\mathbf{A C}_{\mathbf{4}}=\mathbf{F}_{\mathbf{1}} \cdot\left(\mathbf{K}_{\mathbf{1}} \cdot \sum_{i=1}^{i=n} q_{i}\right)
$$

(5) The vendor gains for stocking the emergency stock at his end. The vendor retains emergency stock at his end and as per the points mentioned in 4.2 above, the buyer bears the holding cost for a period till the buyer has utilized the amount

$$
\left(\mathbf{1}+\mathbf{K}_{\mathbf{1}}\right) \cdot \sum_{i=1}^{i=n} q_{i}
$$

Let $\mathrm{D}$ be buyer's consumption rate; at this rate, his stock lasts for a period

$$
\frac{1}{D}\left(1+k_{1}\right) \cdot \sum_{i=1}^{i=n} q_{i}
$$

Let this cost be denoted by $\mathrm{AC}_{5}$.

Holding cost incurred by the buyer on emergency stock $=$ Gain of the vendor

$$
\left.\therefore \quad \mathbf{A C}_{5}=\mathrm{h}_{1} \cdot\left(\mathrm{P}_{1}+\mathrm{C}_{1}\right)\left(\mathrm{K}_{2} \sum_{i=1}^{i=n} q_{i}\right)\right]\left(\frac{1}{D}\left(1+k_{1}\right) \cdot \sum_{i=1}^{i=n} q_{i}\right)
$$

Justifying vendor's approach, the sum of losses must balance the gains. We have $\mathbf{A C}_{3}+\mathbf{A C}_{4}=\mathbf{A C}_{5}$

\subsubsection{What is on buyer's part?} ends.

In this section, we identify different factors of the new set-up of maintenance of additional stock on both 
(6) According to the plan the buyer bears the holding cost of the emergency stock at vendor's end, as being the additional production made in his interest. In addition to this, he also bears a holding cost for the additional amount at his end-Safety plan stock.

The sum of these two costs is an additional burden on the buyer and this is a loss by additional amount of maintenance of stock.

Holding cost incurred by the buyer for maintenance of safety-plan stock at his end, denoted by $\mathrm{AC}_{6}$ is for the period of his utilization of his regular ordered stock .

This time slot is $\left(\sum_{i=1}^{i=n} q_{i}\right) / \mathrm{D}$

This gives $\mathbf{A C}_{6}=\mathrm{h}_{2} . \mathrm{S}_{1} \cdot\left(\mathrm{K}_{1} \cdot \sum_{i=1}^{i=n} q_{i}\right)\left(\sum_{i=1}^{i=n} q_{i}\right) / \mathrm{D}$

Holding cost incurred by the buyer on emergency stock $=$ Gain of the vendor As derived in earlier section; it is $\mathbf{A C}_{5}$

$\left.\therefore \mathbf{A C}_{5}=\mathrm{h}_{1} .\left(\mathrm{P}_{1}+\mathrm{C}_{1}\right)\left(\mathrm{K}_{2} \sum_{i=1}^{i=n} q_{i}\right)\right]\left(\frac{1}{D}\left(1+k_{1}\right) \cdot \sum_{i=1}^{i=n} q_{i}\right)$

The sum total of holding costs incurred by the buyer, denoted by $\mathrm{AC}_{7}$, is

$\mathrm{AC}_{7}=\mathrm{AC}_{5}+\mathrm{AC}_{6}$

(7) The buyer on the other hand, saves $\delta \%$ on the purchase price of the safety-plan stock. Let $\mathbf{S}_{\mathbf{1}}$ be the cost price per unit to the buyer.

Amount saved on the purchase of safety-plan stock $=\mathbf{A C}_{\mathbf{8}}=\left(\mathrm{S}_{1} \cdot(1-\delta / 100)\right) .\left(\mathrm{K}_{1} \cdot \sum_{i=1}^{i=n} q_{i}\right)$

(8) The buyer would have paid interest at the rate $\mathrm{R} \%$ for blocking his capital on an amount till his sales period. The same amount he, probably, has utilized in some other activity which can at least the same or more that would have generated from the interest.

This amounts to

$$
\mathbf{A C}_{9}=s_{1} \cdot(1-\delta / 100)\left(k_{1} \sum_{i=1}^{i=n} q_{i}\right)\left(\frac{\left(1+k_{1}\right) \sum_{i=1}^{i=n} q_{i}}{D}\right)(r)
$$

Where, $\mathrm{D}$ is the buyer's sales rate in his market and $\mathrm{r}=\mathrm{R} / 100$

(9) The buyer, on maintenance of emergency stock at buyer's end and paying holding charges, is confident that would in no cases, run shortages. This situation amounts him worth much boosting his confidence. This gain, in terms of buyer's evaluation of situation is termed as

"No- shortage Gain". This is proportionate to basic cost of emergency stock.

Basic cost of Emergency stock $=\mathrm{S}_{1} \cdot \mathrm{K}_{2} \cdot \sum_{i=1}^{i=n} q_{i}$

If $\beta$ is a factor showing buyer's satisfaction or 'no-shortage gain' then 


$$
\text { Gain cost }=A C_{10}=\beta \cdot S_{1} \cdot K_{2} .1_{i}
$$

We can write a balancing equation for the sum and loss to buyer; it is as follows.

$$
\mathrm{AC}_{7}=\mathrm{AC}_{8}+\mathrm{AC}_{9}+\mathrm{AC}_{10}
$$

Justifying vendor's approach, the sum of losses must balance the gains.

We have $\mathbf{A C}_{3}+\mathbf{A C}_{4}=\mathbf{A C}_{5}$

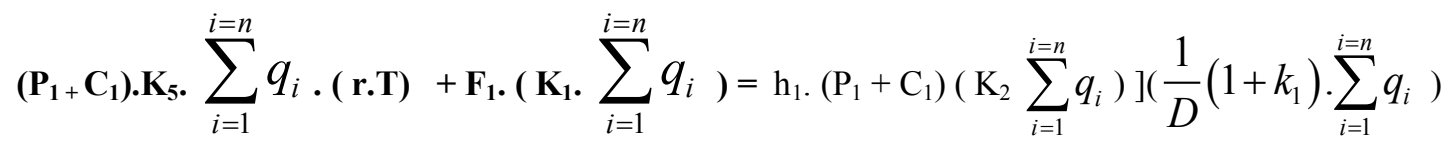

We write $\mathrm{Q}=\sum_{i=1}^{i=n} q_{i}$

We cancel $\mathrm{Q}$ from each term and get the following equation.

$\left(\mathrm{P}_{1}+\mathrm{C}_{1}\right) \cdot \mathrm{K}_{5} \cdot(\mathrm{r} \cdot \mathrm{T})+\mathrm{F}_{1} \cdot \mathrm{K}_{1}=\mathrm{h}_{1} \cdot\left(\mathrm{P}_{1}+\mathrm{C}_{1}\right) \cdot \mathrm{K}_{2}\left(1+\mathrm{K}_{1}\right) \cdot(\mathrm{Q} / \mathrm{D})$

On Simplification,

$\left(\mathrm{P}_{1}+\mathrm{C}_{1}\right)\left[\mathrm{h}_{1} \mathrm{~K}_{2} \cdot \mathrm{Q}\left(1+\mathrm{K}_{1}\right)-\mathrm{D} . \mathrm{K}_{5} \cdot \mathrm{r} . \mathrm{T}\right)=\mathrm{F}_{1} \cdot \mathrm{K}_{1}, \mathrm{D} \quad$ where $\mathrm{K}_{5}=1+\dot{\varnothing}$

Now, for the buyer,

The sum total of holding costs incurred by the buyer, denoted by $\mathrm{AC}_{7}$, is $\mathrm{AC}_{7}=\mathrm{AC}_{5}+\mathrm{AC}_{6}$

$$
\begin{aligned}
\mathbf{A C}_{7} & \left.=\mathrm{h}_{1} \cdot\left(\mathrm{P}_{1}+\mathrm{C}_{1}\right)\left(\mathrm{K}_{2} \sum_{i=1}^{i=n} q_{i}\right)\right]\left(\frac{1}{D}\left(1+k_{1}\right) \cdot \sum_{i=1}^{i=n} q_{i}\right)+\mathrm{h}_{2} \cdot \mathrm{S}_{1} \cdot\left(\mathrm{K}_{1} \cdot \sum_{i=1}^{i=n} q_{i}\right)\left(\sum_{i=1}^{i=n} q_{i}\right) / \mathrm{D} \\
& \left.=\mathrm{h}_{1} \cdot\left(\mathrm{P}_{1}+\mathrm{C}_{1}\right)\left(\mathrm{K}_{2} \mathrm{Q}\right)\right]\left(\frac{1}{D}\left(1+k_{1}\right) \cdot . Q Q\right)+\mathrm{h}_{2} \cdot \mathrm{S}_{1} \cdot\left(\mathrm{K}_{1} \cdot \mathrm{Q}\right)[\mathrm{Q} / \mathrm{D}] \text { where } \mathrm{Q}=\sum_{i=1}^{i=n} q_{i}
\end{aligned}
$$

At this stage, we simplify certain terms that we have already derived above.

Amount saved on the purchase of safety-plan stock $=\mathbf{A C}_{\mathbf{8}}=\left(\mathrm{S}_{1} \cdot(1-\delta / 100)\right) .\left(\mathrm{K}_{1} \cdot \sum_{i=1}^{i=n} q_{i}\right)$

Let $(1--\delta / 100)=\theta$,

$$
\mathrm{AC}_{8}=\theta \cdot \mathrm{S}_{1} \cdot \mathrm{K}_{1} \cdot \mathrm{Q}
$$

The buyer would have paid interest at the rate $\mathrm{R} \%$ for blocking his capital on an amount till his sales period $=\left(\frac{\left(1+k_{1}\right) \cdot Q}{D}\right)$. The same amount he, probably, would have utilized in some other activity which can at least the same or more that would have generated from the interest.

This amounts to

$$
\mathrm{AC}_{9}=s_{1} \cdot \theta\left(k_{1} \cdot Q\right)\left(\frac{\left(1+k_{1}\right) \cdot Q}{D}\right)(r)
$$

Where, $D$ is the buyer's sales rate in his market and $r=R / 100$

$\beta$ is a factor showing buyer's satisfaction or ' no-shortage gain' then 
Gain cost $=\mathbf{A C}_{\mathbf{1 0}}=\boldsymbol{\beta} \cdot \mathbf{S}_{\mathbf{1}} \cdot \mathbf{K}_{\mathbf{2}} \cdot \mathbf{Q}$

As discussed above, we have $\mathbf{A C}_{7}=\mathbf{A C}_{8}+\mathbf{A C}_{9}+\mathbf{A C}_{10}$

$$
\text { Now, } \left.\quad \mathrm{AC}_{7}=\mathrm{h}_{1} \cdot\left(\mathrm{P}_{1}+\mathrm{C}_{1}\right)\left(\mathrm{K}_{2} \mathrm{Q}\right)\right]\left(\frac{1}{D}\left(1+k_{1}\right) \cdot . Q\right)+\mathrm{h}_{2} \cdot \mathrm{S}_{1} \cdot\left(\mathrm{K}_{1} \cdot \mathrm{Q}\right)[\mathrm{Q} / \mathrm{D}]
$$

And $\quad \mathrm{AC}_{8}+\mathrm{AC}_{9}+\mathrm{AC}_{10}=\quad . \mathrm{S}_{1} \cdot \mathrm{K}_{1} \cdot \mathrm{Q}+s_{1} \cdot \theta\left(k_{1} \cdot Q\right)\left(\frac{\left(1+k_{1}\right) \cdot Q}{D}\right)(r)+\quad \beta \mathrm{S}_{1} \cdot \mathrm{K}_{2} \cdot \mathrm{Q}$

Cancelling ' $\mathrm{Q}$ ' from both the sides, and simplifying the equation,

$\left(1+K_{1}\right) \cdot Q \cdot\left\{h_{1} \cdot\left(P_{1}+C_{1}\right) K_{2}-\theta \cdot S_{1} \cdot K_{1} \cdot r\right\}=S_{1} \cdot K_{1} \cdot\left(D \cdot \theta-h_{2} \cdot Q\right)+\beta \cdot S_{1} \cdot K_{2} \cdot D$

As a result, we have two equations, (19) and (20).

We write them;

$$
\begin{aligned}
& \left(P_{1}+C_{1}\right)\left[h_{1} K_{2} \cdot Q\left(1+K_{1}\right)-D \cdot K_{5} \cdot r \cdot T\right)=F_{1} \cdot K_{1}, D \quad \text { where } K_{5}=1+\varnothing \\
& \left(1+K_{1}\right) \cdot Q \cdot\left\{h_{1} \cdot\left(P_{1}+C_{1}\right) K_{2}-\theta \cdot S_{1} \cdot K_{1} \cdot r\right\}=S_{1} \cdot K_{1} \cdot\left(D \cdot \theta-h_{2} \cdot Q\right)+\beta \cdot S_{1} \cdot K_{2} D
\end{aligned}
$$

These are the equations in terms of unknown $\mathrm{K}_{1}$ and $\mathrm{K}_{2}$.

For a known value of $Q, K_{1} Q$ and $K_{2} Q$ will determine the values of safety - Plan and the emergency stock.

\begin{tabular}{|c|c|c|c|c|c|c|c|c|c|c|c|c|c|c|c|c|}
\hline \\
\hline & \multicolumn{14}{|c|}{ Assumed Values } & \multicolumn{2}{|c|}{ Derived Values } \\
\hline Case & $\mathrm{D}$ & $\mathrm{r}$ & $\mathrm{Q}$ & S1 & $\mathrm{C} 1$ & $\varphi$ & $\theta$ & $\mathrm{P}$ & $\mathrm{B}$ & $\mathrm{fl}$ & K5 & h1 & $\mathrm{h} 2$ & $\mathrm{~T}$ & $\mathrm{~K} 1$ & $\mathrm{~K} 2$ \\
\hline 1 & 25 & 0.03 & 1000 & 5 & 1 & 0.01 & 0.9 & 1 & 1 & 0.5 & 1.01 & 0.03 & 0.06 & 1 & 0.314 & 0.069001 \\
\hline 2 & 16 & 0.06 & 1000 & 4 & 1 & 0.01 & 0.75 & 1 & 1 & 0.5 & 1.01 & 0.03 & 0.06 & 1 & 0.068 & 0.038752 \\
\hline 3 & 20 & 0.01 & 1000 & 5 & 1 & 0.01 & 0.9 & 1 & 2 & 0.5 & 1.01 & 0.02 & 0.04 & 1 & 0.5978 & 0.023632 \\
\hline 4 & 25 & 0.01 & 1000 & 4 & 1 & 0.01 & 0.75 & 1 & 2 & 0.5 & 1.01 & 0.02 & 0.04 & 1 & 0.18 & 0.058369 \\
\hline 5 & 50 & 0.03 & 1000 & 4 & 1 & 0.01 & 0.7 & 1 & 1 & 0.5 & 1.01 & 0.06 & 0.065 & 1 & 0.107 & 0.042946 \\
\hline
\end{tabular}

We take an illustration and try to modify the results in different cases.

\subsection{ILLUSTRATIONS:}

As shown above, in Case 1, the Vendor maintains the Safety Plan stock of $31.4 \%$ at the buyer's end and Emergency Stock of $6.9 \%$ at his own end. By doing this, he can ensure that the essential pharmaceutical products are consistently available at the buyer's end. The Vendor makes additional supply of $31.4 \%$ to the buyer, this additional quantity being offered to buyer at $10 \%$ discount. Again the vendor maintains an emergency stock of $6.9 \%$ at his warehouse, with a holding cost to the buyer. By this arrangement, it is ensured that optimum inventory is maintained to prevent stock shortages.

\section{Effect of discount ${ }_{5}$ on decision variable $K_{1}$ and $K_{2}$}

Following values of $\mathrm{K}_{1}$ and $\mathrm{K}_{2}$ were observed for the values of e. $_{\text {. }}$

The assumed values were

\begin{tabular}{|c|c|c|c|c|c|c|c|c|c|c|c|c|c|}
\hline $\mathrm{D}$ & $\mathrm{r}$ & $\mathrm{Q}$ & $\mathrm{S}_{1}$ & $\mathrm{C}_{1}$ & $\varphi$ & $\theta$ & $\mathrm{P}$ & $\mathrm{B}$ & $\mathrm{f}_{1}$ & $\mathrm{~K}_{5}$ & $\mathrm{~h}_{1}$ & $\mathrm{~h}_{2}$ & $\mathrm{~T}$ \\
\hline 20 & 0.01 & 1000 & 5 & 1 & 0.01 & 0.876 & 0.5 & 2 & 0.5 & 1.01 & 0.02 & 0.04 & 1 \\
\hline
\end{tabular}

\begin{tabular}{|c|c|c|}
\hline & $\mathrm{K}_{1}$ & $1-\theta$ \\
\hline 0.876 & 0.11 & 0.124 \\
\hline 0.886 & 0.12 & 0.114 \\
\hline 0.891 & 0.13 & 0.109 \\
\hline 0.899 & 0.14 & 0.101 \\
\hline 0.904 & 0.15 & 0.096 \\
\hline 0.909 & 0.16 & 0.091 \\
\hline
\end{tabular}




\begin{tabular}{|r|r|r|}
\hline 0.913 & 0.17 & 0.087 \\
\hline 0.917 & 0.18 & 0.083 \\
\hline 0.92 & 0.19 & 0.08 \\
\hline 0.923 & 0.2 & 0.077 \\
\hline 0.925 & 0.21 & 0.075 \\
\hline 0.927 & 0.22 & 0.073 \\
\hline 0.929 & 0.23 & 0.071 \\
\hline 0.931 & 0.24 & 0.069 \\
\hline 0.932 & 0.25 & 0.068 \\
\hline
\end{tabular}

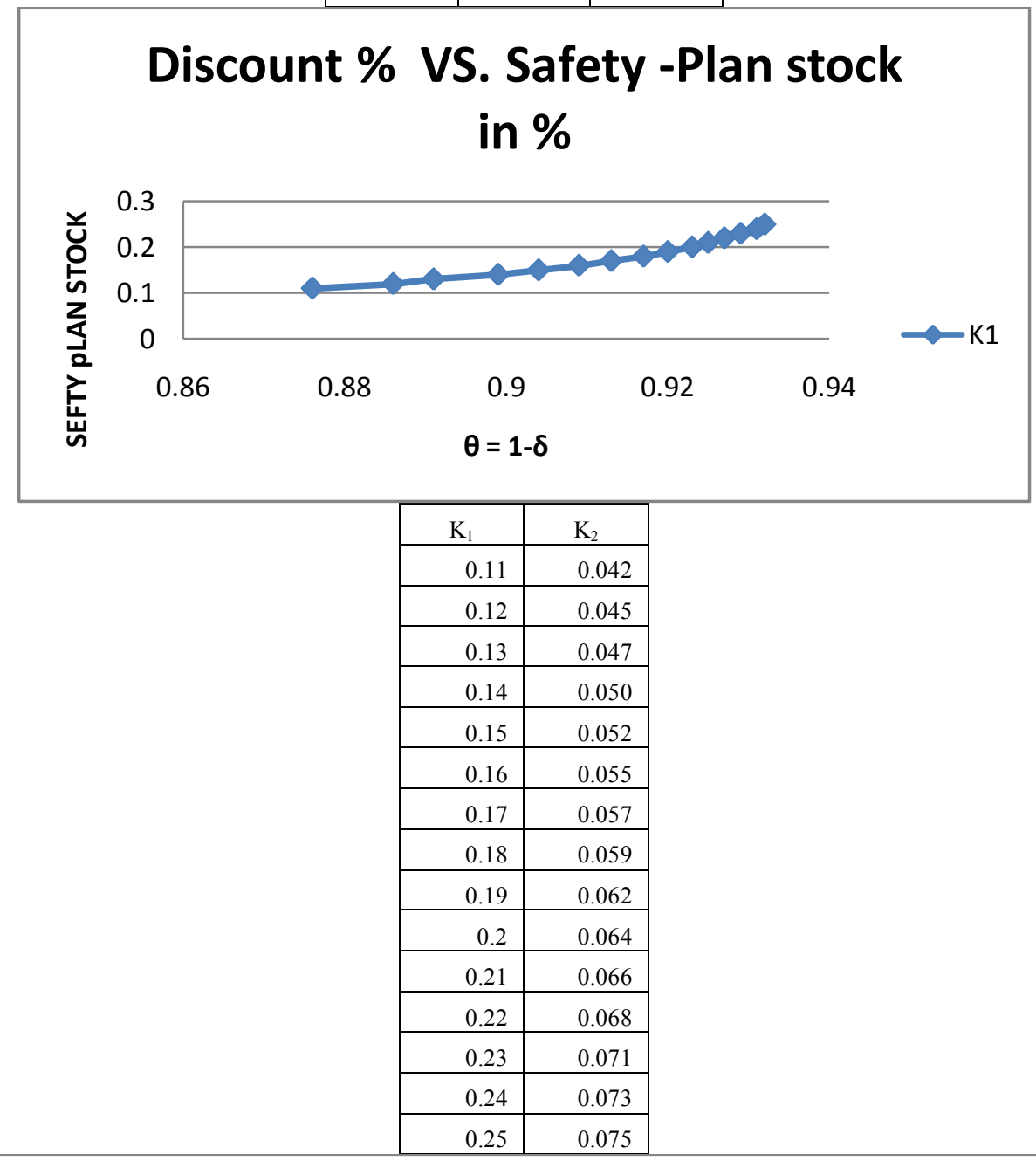

\section{Safety Plan stock \% vs. Emergency Stock in \%}

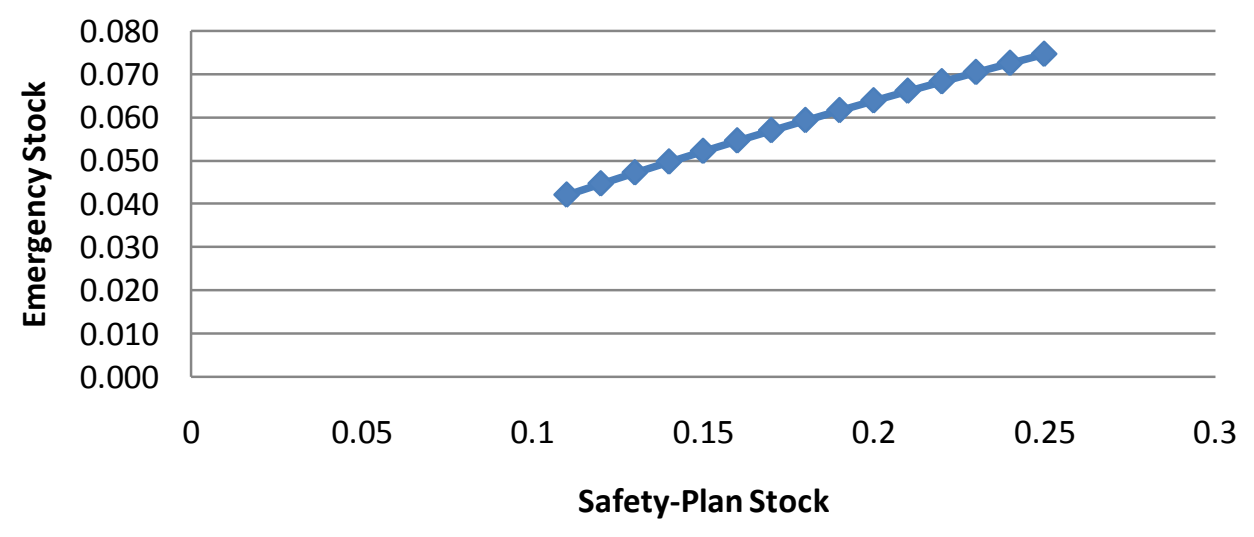




\begin{tabular}{|r|r|}
\hline \multicolumn{1}{|c|}{$1-\theta$} & \multicolumn{1}{|c|}{$\mathrm{K}_{1}$} \\
\hline 0.124 & 0.11 \\
\hline 0.114 & 0.12 \\
\hline 0.109 & 0.13 \\
\hline 0.101 & 0.14 \\
\hline 0.096 & 0.15 \\
\hline 0.091 & 0.16 \\
\hline 0.087 & 0.17 \\
\hline 0.083 & 0.18 \\
\hline 0.08 & 0.19 \\
\hline 0.077 & 0.2 \\
\hline 0.075 & 0.21 \\
\hline 0.073 & 0.22 \\
\hline 0.071 & 0.23 \\
\hline 0.069 & 0.24 \\
\hline 0.068 & 0.25 \\
\hline
\end{tabular}

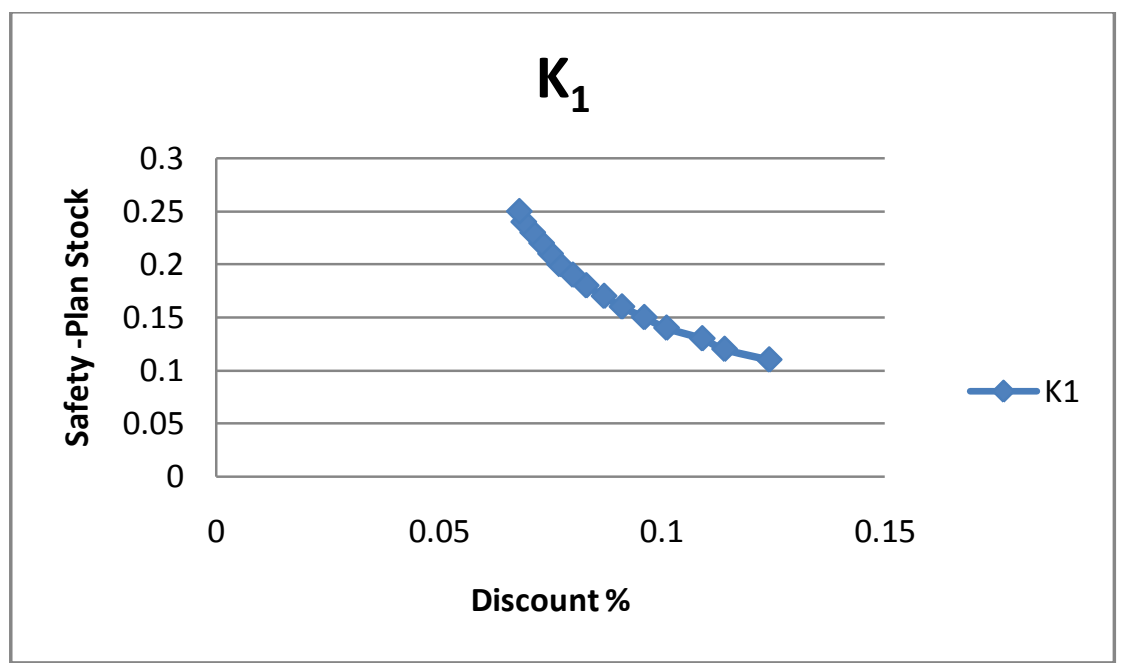

II. Conclusions:

This study has opened new horizons of some prime and core concepts which are already hidden within the fundamental aptitude of management concepts of marketing and keeping a fair control on planning, production, distribution channel and finally to reach up to the end- seller (the buyer). The study has used established concepts of VMI (Vendor Managed Inventory) and CPFR (Collaborative Planning, Forecasting and Replenishment) and proposed two novel decision variables- Safety Plan (Stock) and Emergency Stock. The study has further proposed a model to optimize the two quantities for a win-win situation for the vendor and the buyer. Thus a novel basis of collaborative production planning and stocking has been proposed in this study.

The concepts are basically the derivatives of the most successful plans following VMI (Vendor Managed Inventory). This study proposes a model that optimizes solutions for arriving at production planning and stocking of essential medicines at the vendor's end and buyer's end to avoid stock-out situations.

The study designed the models and after a series of meetings and extensive discussions, what has come out, is represented in this study. It has been tried and implemented in some cases where we got the chance of direct coordination with buyers.

The new bubbling concepts like (1) Safety- Plan( stock) (2) Emergency stock, and (3) No- shortage gain are the newly thought and designs of the old pattern of ROL and safety stock and buffer stock but here at different level and on the basis of sharing responsibilities. In many cases, as found, over-whelming response because of the two major reasons (1) Safety Plan stock has been given a good and profitable discount over the carrying charges, and (2) The said stock is within the operational control of the buyer.

The graphs also strengthen the intuitively felt observations that: 
(1) As the vendor decreases the discount $\%$ on the sale price of the Safety Plan stock, the buyer demands more amount of this additional stock.

The reasons for this are obvious and logical in win-win situation as expected and core-built notion of the paper.

(2) Approximately linear and unidirectional sympathetic change exists between the $\%$ values of $\mathrm{K}_{1}$ and $\%$ values of $\mathrm{K}_{2}$.

(3) As the bank rate increases, buyer demand for higher discount rate increases.

A minor variation and corresponding adjustments has been reflected in the illustration that clarifies the core techniques of determination of the Safety- Plan quantity and Emergency stock quantities to be determined by the vendor. We are still in process of designing and verifying some new concepts that have already taken sound position in our thoughts over these issues.

\section{References:}

[1]. Goyal,S,K. (1995), A one-Vendor multi-buyers integrated inventory model - A comment, European Journal of operation Research, 82, 209-210

[2]. Jha, Pradeep, J (June-2013), Buyer- Vendor integrated system- the technique of EOQ dependent shipment size to achieve steady level and cost minimization, ISOR Journal of Mathematics( ISOR-JM), 46-57

[3]. Rajmanohar, T,P, (2008), Inventory Optimization Introduction, The ICFAI University Press 